\title{
Alterações na expressão de genes para citocinas, fatores de cresci- mento e seus receptores estão associadas com as neoplasias epiteliais ovarianas
}

\section{Changes in gene expression for cytokines, growth factors and their receptors are associated with epithelial ovarian cancer}

Ana Élida Nogueira Souza1', Maria Irisleide Diógenes Bezerra Esmeraldo¹, Vinícius Ramalho Dantas Araújo², José Roberto Viana Silva ${ }^{3}$

\begin{abstract}
RESUMO
O câncer de ovário é o câncer ginecológico de maior letalidade e mais difícil de ser diagnosticado. Cerca de $3 / 4$ dos tumores malignos de ovário apresentam-se em estágio avançado no momento do diagnóstico inicial. A etiologia do câncer de ovário parece ser multifatorial, incluindo fatores reprodutivos, familiares e pessoais. Diversos fatores envolvidos no desenvolvimento do câncer de ovário vêm sendo estudados, buscando melhor entender seu desenvolvimento. $O$ tumor originado do epitélio superficial do ovário é o tipo mais frequente e tem sido associado com alterações na expressão de kit ligante (KL), do receptor de fator epidermal de crescimento (EGF-R), assim como a super expressão e ativação de genes como o HER, myc, ras e p53. O objetivo desta revisão é descrever as características dos tipos de tumores ovarianos e discutir a influência das gonadotrofinas e as alterações na expressão de genes para citocinas, fatores de crescimento e seus receptores nas neoplasias ovarianas.
\end{abstract}

Palavras-chave: Câncer de Ovário. Expressão Gênica. Marcadores Biológicos. Neoplasias Epiteliais Malignas.

\section{Introdução}

O câncer ovariano está entre as neoplasias ginecológicas mais comuns e é a quinta principal causa de morte por câncer entre as mulheres. ${ }^{1}$ Os carcinomas ovarianos representam um grupo heterogêneo de neoplasias que são classificadas em subgrupos de acordo com tipo e grau de diferenciação. Embora o mane-
1. Médica

2. Estudante de medicina

3. Doutor em Biologia da Reprodução, professor de Histologia e Embriologia da Universidade Federal do Ceará.
Correspondência: Universidade Federal do Ceará, Campus Sobral - Curso de Medicina, Programa de Pós-Graduação em Biotecnologia, Avenida Comandante Maurocélio Rocha Pontes, 100- Derby, CEP: 62.042-280, Sobral, CE, Brasil.

Artigo recebido em 21/03/2011 Aprovado para publicação em 14/09/2012 
jo clínico atual do carcinoma de ovário, em grande parte, não considere essa heterogeneidade, torna-se evidente que cada tipo possui defeitos genéticos específicos que desregulam as vias de sinalização nas células tumorais. ${ }^{2}$ A classificação dos tumores ovarianos epiteliais é baseada principalmente na morfologia celular e os quatro tipos principais de tumores epiteliais são os serosos, os de células claras, o endometrióide e os mucinosos. De um modo geral, para o tratamento dos vários tipos de câncer de ovário são utilizados quimioterápicos que destroem o pool de folículos imaturos, o que reduz drasticamente o potencial reprodutivo, especialmente em mulheres jovens. ${ }^{3}$

Sabe-se que o prognóstico é cada vez mais sombrio quando é detectado a presença de metástases. Já foi relatado que a disseminação peritoneal de câncer de ovário em torno de órgãos abdominais depende do movimento das células cancerosas, que são regulados de forma autócrina ou parácrina por fatores de crescimento e citocinas presentes no líquido peritoneal. ${ }^{4}$ O aumento da expressão gênica de citocinas, vários fatores de crescimento e de seus receptores é bastante comum em muitos tipos de câncer, incluindo câncer epitelial de ovário. ${ }^{5}$ Além disso, os hormônios folículos estimulante (FSH) e luteinizante (LH) estimulam o crescimento de epitélio normal, de epitélio imortalizado da superfície do ovário e de várias linhagens de células cancerígenas ovarianas. ${ }^{5}$ Desta forma, o objetivo desta revisão é descrever as características dos tumores epiteliais ovarianos e discutir a influência das gonadotrofinas FSH e LH na carcinogênese ovariana e as alterações de expressão de genes nos diferentes tipos de tumores.

\section{Tipos de câncer de ovário}

Seidman et al. (2004) ${ }^{6}$ analisaram 220 casos de carcinoma ovariano / peritoneal e demonstraram que quase $70 \%$ eram tumores serosos, enquanto que menos de 5\% apresentavam-se confinados a um ou ambos os ovários no momento do diagnóstico. A atipia nuclear e a atividade mitótica abundante foram as características mais comumente observadas. Os adenocarcinomas endometrióides representavam apenas $7 \%$ e tinham características morfológicas semelhantes às dos seus homólogos do endométrio, ou seja, mostravam quantidades variadas de formação de glândulas, e por vezes, acompanhadas de diferenciação escamosa. Em contraste com os carcinomas serosos, mais de $50 \%$ dos adenocarcinomas endometrióides estavam confinados aos ovários no momento do diagnóstico, sendo que a atipia nuclear geralmente é menos pronunciada. Além disso, aproximadamente $10 \%$ dos carcinomas de ovário apresentaram diferenciação de células claras, sendo que vários tipos de crescimento foram reconhecidos, como por exemplo, sólido, papilar, túbulo-cístico. Já os carcinomas mucinosos compostos representavam menos de $3 \%$ dos carcinomas primários do ovário e são quase sempre confinadas ao ovário no momento do diagnóstico. Os adenocarcinomas mucinosos também mostram formação glandular evidente, o que contrasta com os adenocarcinomas endometrióides. ${ }^{6}$

Aproximadamente $90 \%$ dos tumores malignos primários do ovário são epiteliais (carcinomas) e surgem a partir do epitélio da superfície do ovário, ou seja, mais provavelmente a partir de cistos epiteliais. ${ }^{1}$ Alguns pesquisadores têm sugerido que eles se desenvolvem a partir do sistema secundário de Müller, que inclui cistos ovarianos e endometriose. ${ }^{7}$ Alguns estudos têm demonstrado um prognóstico relativamente desfavorável desses tumores no tipo de câncer de ovário de células claras. ${ }^{8}$ Além disso, muitas análises clínicas e moleculares de adenocarcinomas mucinosos de ovário são comprometidas devido à inclusão involuntária de adenocarcinoma metastático, que frequentemente surge a partir do trato gastrointestinal e migra para os ovários. ${ }^{9}$

\section{Alterações hormonais e o câncer de ovário}

\subsection{FSH e LH}

O crescimento de folículos ovarianos e a diferenciação das células da granulosa são processos complexos dependentes das gonadotrofinas pituitárias FSH e LH. ${ }^{10}$ Em folículos pequenos, o FSH regula a proliferação das células da granulosa por meio da modulação da expressão ciclina D2, que é um importante regulador do ciclo celular. ${ }^{11} \mathrm{JI}$ et al. (2004) ${ }^{12}$ demonstraram que um aumento da expressão de receptores de FSH em células ovarianas promove um aumento da proliferação celular. Além disso, a estimulação com FSH aumenta a expressão de oncogenes e reduz a expressão de genes supressores de tumor. Além disso, há evidências que sugerem que hormônio folículo estimulante (FSH) pode facilitar a neovascularização de câncer de ovário através do aumento da expressão do fator de crescimento endotelial vascular (VEGF) 
nas células cancerígenas. ${ }^{13} \mathrm{Tem}$ sido relatado ainda que o FSH aumenta a invasão tumoral e a adesão através da regulação da expressão de metaloproteinases (MMP), bem como subunidade de integrina $\alpha$ e CD44 em células de câncer de ovário. ${ }^{14}$ Em pacientes com cistos ovarianos malignos, as concentrações de FSH e LH no líquido retirado do cisto estão aumentadas e próximas das concentrações plasmáticas. Já em cistos benignos, as concentrações de gonadotrofinas estão sempre baixas. Entretanto, não existe diferença nas concentrações sanguíneas de gonadotrofinas entre pacientes com cistos malignos com benignos. ${ }^{15}$

Já os tumores de células da granulosa exibem um fenótipo interessante, pois exibem características morfológicas e funcionais muito próximas das células da granulosa em proliferação de folículos ovarianos normais. Essas similaridades incluem: afinidade ${ }^{16} \mathrm{e}$ responsividade ao $\mathrm{FSH}^{17}$, bem como a secreção de hormônios gonadais e de inibina. ${ }^{18,19}$ A síntese de inibina por esses tumores é associada a uma diminuição nos níveis de FSH plasmáticos ${ }^{19}$, sugerindo que a inibina é biologicamente ativa e que o crescimento tumoral é independente de $\mathrm{FSH}^{20}$

\section{Alterações na expressão de ge- nes e o câncer de ovário}

\subsection{Fator de crescimento epidermal (EGF) e seus receptores}

A família do fator de crescimento epidermal (EGF) abrange vários membros, incluindo o próprio EGF, o fator de crescimento transformante alfa (TGF alfa), o EGF ligado a herarina (HD-EGF), a anfirregulina, a epirregulina, a betacelulina e as neoregulinas. ${ }^{21}$ Todos esses fatores de crescimento exercem suas funções ligando-se a quatro diferentes receptores de alta afinidade: EGFR/ErbB1, HER2/ErbB2, HER3/ ErbB3 e HER4/EbrB4. A super-expressão desses receptores, em particular do HER2, é frequentemente encontrada em cânceres humanos. ${ }^{22}$ Os receptores de EGF regulam processos importantes na carcinogênese, incluindo a sobrevivência celular, progressão do ciclo celular, invasão tumoral e angiogênese. Os ligantes vinculam-se ao EGFR ativando a transdução de sinal que regula para cima os fatores de transcrição, levando ao estímulo do crescimento celular. ${ }^{23}$

Outra característica peculiar do EGF é sua potente ação mitogênica no mesotélio ovariano ${ }^{24}$, local onde há uma significativa expressão desse fator de crescimento e de seu receptor. ${ }^{25}$ Dependendo do tipo de célula, a ligação do EGF ao EGFR induz várias cascatas ativadoras que podem resultar em várias respostas celulares que incluem mitose, secreção de proteínas, diferenciação e aquisição de motilidade. ${ }^{26}$ Além disso, o EGF pode induzir várias alterações celulares, como por exemplo, alterações na morfologia, polaridade e adesão celulares, bem como o desenvolvimento de formas celulares semelhantes aos fibroblastos. Estes eventos são decorrentes da reorganização do citoesqueleto e da produção de proteases que facilitam o processo de migração e invasão celular. ${ }^{27}$ Assim, uma maior expressão de EGFR é encontrada em $35-70 \%$ de todos os cânceres ovarianos primários. ${ }^{28}$

$\mathrm{O}$ receptor do fator de crescimento epidérmico (EGFR) é altamente expresso em carcinomas de ovário e a ativação direta ou indireta desse receptor é capaz de provocar o crescimento do tumor. ${ }^{29}$ Portanto, a amplificação do gene, mutação genética e transcrição ou tradução alteradas resultam na expressão aberrante de EGFR, que contribui para a transformação maligna, mau prognóstico e diminuição da capacidade de resposta terapêutica em pacientes com câncer de ovário. ${ }^{30} \mathrm{O}$ receptor do fator de crescimento epidérmico (EGFR) é altamente expresso em carcinomas de ovário, sendo a ativação direta ou indireta de EGFR capaz de provocar o crescimento do tumor ${ }^{29}$, pois são ativadas diversas vias de sinalização nas células tumorais. ${ }^{27,31} \mathrm{O}$ aumento da expressão do receptor do fator de crescimento epidérmico (EGFR) e de seus ligantes é comumente observado em muitos tipos de câncer, incluindo câncer epitelial de ovário. ${ }^{5} \mathrm{O}$ EGF e seu receptor (EGFR) atuam de forma autócrina e parácrina para regular a proliferação das células tumorais. A compreensão dos mecanismos de ação do EGF nas células tumorais é de grande importância para o desenvolvimento de quimioterápicos para vários tipos de câncer. ${ }^{32}$

\subsection{Interleucina-6 e seu receptor}

A Interleucina-6 (IL-6) é uma glicoproteína que age através de um complexo receptor de citocinas alfa (gp80) e de um transdutor de sinal gp130. Em seguida, a IL-6 utiliza cascata de sinalização Jak / STAT Ras / MAPK e PI3K-Akt. ${ }^{33,34}$ Vários relatos têm indicado que a IL-6 é importante na carcinogênese ovariana. Além disso, experimentos in vitro demonstraram que células epiteliais de câncer de ovário constitutivamente produzem IL-6, modulando a resposta imune do hospedeiro ao câncer dos ovários. ${ }^{35} \mathrm{O}$ au- 
mento da expressão de alfa IL-6R, STAT3 e a ativação constitutiva também foram encontradas em associação com a proliferação celular nas neoplasias ovarianas. ${ }^{36}$ Para reforçar a importância da IL-6 nas neoplasias ovarianas, Coward et al. $(2011)^{37}$ realizaram um estudo imunohistoquímico em amostras de tecidos de 221 casos de câncer de ovário. Estes autores demonstraram que a presença de IL-6 em células malignas de câncer ovariano está associada a um mau prognóstico. Além disso, foi demonstrado que a IL-6 estimula a produção de citocinas inflamatórias, a angiogênese tumoral e a infiltração tumoral de macrófagos no tecido ovariano neoplásico Outros autores também relataram que elevados níveis de IL-6 no líquido ascítico de mulheres com câncer ovariano predizem uma menor sobrevida nessas pacientes. ${ }^{38}$

\subsection{Receptores ativados por proliferadores de peroxissoma (PPARs)}

Os receptores ativados por proliferadores de peroxissoma (PPARs) são membros da superfamília de receptores nucleares. ${ }^{39}$ As três isoformas intimamente relacionados de PPAR foram identificadas como PPARa (NR1C1), PPARb (NR1C2) e PPARg (NR1C3) são codificados por genes separados e desempenham funções específicas. ${ }^{40}$ Como fatores de transcrição que exigem ativação, os PPARs modulam a expressão de genes alvo no citoplasma ou no núcleo em resposta aos ligantes. Os ligantes dos PPARs fisiológicos incluem os ácidos graxos e seus derivados, como por exemplo, os leucotrienos e as prostaglandinas. A função de PPARb depende da atividade dos seus supostos alvos na cascata e PDK1, o qual atua como oncogenes quando expresso em células epiteliais mamárias. ${ }^{41}$

Ahmed (2008) $)^{42}$ mostrou a associação de PPARb com câncer, quando examinou-se a expressão de PPARb em ovários normais e em diferentes graus histológicos de tumores boderline de ovários, bem como em tumores ovarianos serosos, mucinosos, endometrióides e de células claras. Tanto o tecido ovariano normal, como os que apresentavam tumores benignos ou borderline mostraram-se positivos para PPARb, que se localizava no epitélio e no estroma. A marcação é predominantemente nuclear, mas um certo grau de coloração citoplasmática também é evidente. Aproximadamente $20 \%$ dos tumores das classes 2 e 3 não apresentou coloração para PPARb, enquanto que os demais exibiram algum grau de marcação nuclear e citoplasmática disperso no epitélio e no estroma. A marcação para PPARb no epitélio e no estroma foi significativamente diferente entre o ovários normais e aqueles acometidos com neoplasias. Estes dados sugerem que ao contrário do cólon, endométrio, carcinomas de cabeça e pescoço, a super expressão de PPARb não ocorre em todos os tipos de tumores ovarianos. ${ }^{42}$

Yokoyama et al. $(2007)^{43}$ indicaram que ligantes de PPARa produzem efeitos antitumorais potentes contra câncer de ovário, promovendo a indução de apoptose e diminuição dos níveis de prostaglandina 2 , em conjunto com uma redução da angiogênese por meio da diminuição da expressão de VEGF. Portanto, ligantes de PPARa podem ser agentes eficazes no combate ao câncer do ovário. Em adição, Kim et al. $(2011)^{44}$ sugerem que ligantes de PPARg podem induzir a supressão do crescimento de células de câncer de ovário e mediar a expressão de p63 e p73, conduzindo a uma maior apoptose e maior inibição do crescimento. Os efeitos supressores de tumor dos ligantes de PPARg podem, portanto, ter aplicações no tratamento de câncer de ovário.

\subsection{Quinase dependente de fosfoinosití- deos-1 (PDK1)}

A quinase dependente de fosfoinositídeos-1 (PDK1) é uma proteína quinase que tem vários substratos. Esta proteína foi identificada pela sua capacidade de fosforilar e ativar a proteína quinase $\mathrm{B}$ (PKB, também conhecido como Akt). O estudo da PDK1 é importante, pois ela apresenta um grande aumento de expressão em carcinomas de ovário. ${ }^{45}$ Ahmed $(2008)^{42}$ demonstrou que a associação de PDK1 com o câncer. Este autor avaliou a expressão de PDK1 em ovários normais e em diferentes graus histológicos dos tumores ovarianos e demonstrou que PDK1 estava ausente em 90\% dos ovários normais, mas uma fraca marcação para PDK1 foi observada em $40 \%$ dos tumores benignos de ovário. Além disso, todos os tumores borderline e os malignos de ovário mostraram coloração de PDK1 na membrana citoplasmática. ${ }^{42}$ De um modo geral, diferentes colorações para PDK1 foram observadas entre tumores ovarianos malignos, benignos e borderline. Os dados sugerem que ao contrário do cólon, endométrio, carcinomas de cabeça e pescoço, a super expressão de PDK1 é evidente em tumores ovarianos de baixo para alto grau de malignidade. ${ }^{42}$

No tocante à inibição da proteína PDK-1, Lu et al. $(2010)^{46}$ mostraram que a redução da produção de PDK1 por RNAi em melanomas e em linhas de célu- 
las de câncer de cólon ativados pela via MAPK resulta em significativa inibição do crescimento celular e no aumento das taxas de apoptose. Além disso, Choi et al. $(2008)^{47}$ demonstraram que a inibição da PDK1 resulta na supressão do crescimento celular induzido por EGF e na promoção de apoptose em células humanas de câncer de ovário, concluindo que inibidores da PDK1 poderiam ser eficazes no tratamento desse tipo de câncer.

\subsection{Fatores de crescimento de fibroblastos (FGF)}

Os FGFs representam uma família de fatores de crescimento envolvidos na angiogênese, na cicatrização de feridas e no desenvolvimento embrionário. Esta família é constituída por mais de 20 membros $^{48} \mathrm{e}$ muitos FGFs possuem um amplo espectro mitogênico. Eles estimulam a proliferação de várias células de origem exodérmica, mesodérmica e endodérmica. ${ }^{49}$ Além disso, os FGFs também regulam a migração e a diferenciação de suas células-alvo. ${ }^{48}$

O protótipo de uma família com 23 membros, o FGF-2 é um fator angiogênico dependente de sulfato de heparina para sua atividade biológica. ${ }^{50} \mathrm{~A}$ angiogênese induzida por FGF-2 é de fundamental importância para a formação dos corpos lúteos ${ }^{51} \mathrm{em}$ virtude da proliferação de capilares que acompanha a seleção do folículo pré-ovulatório. ${ }^{52}$

Além disso, o FGF-2 foi relacionado ao fenótipo de vários tipos de cânceres ${ }^{53}$, principalmente aqueles mais dependentes de neovascularização. Estudos anteriores investigaram a resposta e a expressão de FGF2 e de seu receptor em uma variedade de linhagem de células ovarianas malignas. Muitas linhagens responderam ao FGF-2 com um aumento na proliferação celular e na expressão de seu RNAm. ${ }^{54}$ Os níveis de RNAm do FGF-2 também estavam aumentados significativamente em ovários com cânceres quando comparados com ovários normais, sugerindo que o FGF-2 seja uma citocina marcadora de câncer ovariano. ${ }^{54,55}$ Segundo estudos recentes, a amplificação ou a mutação do gene que codifica o receptor FGFR2 ocorre em câncer de estômago, câncer de pulmão, câncer de mama, câncer de ovário e câncer de endométrio. ${ }^{56}$

\subsection{Fator de crescimento semelhante à insu- lina (IGF)}

$\mathrm{O}$ fator de crescimento semelhante à insulina (IGF) I e II são potentes estimuladores de mitose e de sobrevivência em diferentes tipos celulares, exercen- do suas funções de maneira endócrina, parácrina e/ou autócrina. Suas ações são mediadas através do receptor tipo I de IGF, uma tirosina quinase semelhante ao receptor de insulina. Além disso, o IGF II também se liga ao receptor tipo II de IGF que resulta na internalização e degradação do IGF II. ${ }^{57} \mathrm{O}$ gene humano do IGF-II é altamente expresso em vários tipos de tumores malignos humanos, sugerindo que o IGF-II atue como um sinal secundário na carcinogênese. ${ }^{58}$

O IGF-I e suas proteínas de ligação promovem proliferação celular e inibem a apoptose. O IGF-I também estimula o crescimento e o potencial invasivo da célula ovariana, o que sugere sua participação na etiologia do câncer de ovário. Embora haja dados conflitantes a respeito da influência do IGF-I no câncer ovariano, estudos recentes demonstraram uma significativa associação dos níveis plasmáticos de IGF-I com o câncer de ovário ${ }^{59}$ Além disso, foi demonstrado que a secreção de IGF-I por células cancerosas de ovário resistentes a cisplatina medeia a resistência a esta droga em mulheres com câncer de ovário. ${ }^{60}$

\subsection{Kit ligante $(K L)$}

O kit ligante (KL) é um fator de crescimento que exerce seus efeitos nas células-alvo através de ligações com seu receptor c-Kit. Tanto o KL quanto o c-Kit são ativamente expressos por uma variedade de linhagens celulares distintas durante a embriogênese e na vida adulta. Várias funções do KL e do c-Kit na gametogênese, na melanogênese e na hematopoiese já foram descritas. ${ }^{61}$

Nos humanos, mutações no gene do c-Kit podem resultar em piebaldismo, uma doença benigna autossômica dominante que causa uma deficiência na pigmentação. ${ }^{62}$ Defeitos no gene do c-Kit estão também associados a cânceres humanos, incluindo mastocitose $^{63}$ e tumores gastrointestinais. ${ }^{64}$ Além disso, Cheng et al (2010) ${ }^{65}$ demonstraram que mutações no gene c-Kit estão associadas a estágios avançados de tumores ovarianos denominados disgerminomas, pois tais alterações estão presentes em aproximadamente um terço dos casos. A expressão de c-Kit e de KL está presente em vários estágios de câncer ovariano. O KL parece exercer maior função nos estágios primários. Nos estágios mais avançados, sugere-se que a expressão de KL pode estar reduzida ou ausente. A presença de níveis detectáveis de KL em todos os estados de câncer ovariano sugere que a expressão de KL deve contribuir para o desenvolvimento e progressão da doença. ${ }^{66}$ 


\subsection{Janus quinase (JAK) / transdutor de sinal e ativador da transcrição (STAT) - (Ref. Karen)}

A via de sinalização Janus quinase (JAK) / sinal transdutor e ativador de transcrição (STAT) é necessária para diversos processos durante a embriogênese $^{67}$ e a ativação e desta via tem sido associado com câncer ${ }^{68}$, visto que STAT3 tem um importante papel na sobrevivência e na proliferação de células cancerosas. ${ }^{69}$ Esta via é ativada quando um ligante extracelular se liga ao seu receptor, resultando em ativação de JAK e fosforilação de resíduos específicos de tirosina no receptor. As proteínas dos sinais transdutores e ativadores de transcrição (STAT) são recrutadas para o receptor através da ligação a resíduos de tirosina fosforilada. O STAT é então fosforilado por JAK e após o transporte para o núcleo ele funciona como um fator de transcrição. A Interleucina (IL-6), a oncostatina $\mathrm{Me}$ o fator inibidor de leucemia (LIF) agem através de receptores que compartilham uma subunidade do receptor comum GP130, sinalizando através de JAK2 e STAT $3 .{ }^{70} \mathrm{O}$ STAT também pode ser ativado pelo receptor do fator de crescimento epidermal (EGFR), que é necessário para mediar à proliferação das células cancerosas e carcinogênese..$^{71,72}$

Chen et al. (2007) ${ }^{68}$ mostraram que a ativação de STAT 3 é necessária para manter a proliferação das células cancerosas. A inibição da STAT3 levou à inibição do crescimento de várias linhagens de células de câncer ${ }^{68}$, incluindo o câncer de ovário. ${ }^{73}$ No entanto, mutações que ocorrem naturalmente em proteínas STAT3 e que resultam em ativação constitutiva não foram identificadas, sugerindo que a sinalização aberrante STAT3 é freqüente em câncer. A inibição da via de sinalização STAT3 provoca supressão do crescimento de linhagens celulares de cânceres de ovário e de mama. Além disso, a inibição da via STAT3 em diversos modelos de malignidades humanas induz parada do crescimento e apoptose, o que demonstra a associação da via STAT3 a carcinomas de alto grau. ${ }^{69}$

Colomiere et al. (2009) $)^{74}$ demonstraram que há ativação significativa de ambos os transdutores de sinal e ativador de transcrição (STAT) 3 e de Janus quinase (JAK) 2 em ovário com carcinomas de alto grau em comparação com ovários normais ou com tumores benignos. A associação entre a ativação STAT3 e EGF na mediação do fenótipo migratório das células do câncer de ovário foi investigada por mediar transição epitélio-mesenquimal (TEM) de câncer de ovário. As células cancerígenas expressam recepto- res de interleucina-6 (IL-6R) e o tratamento com EGF resultou em aumento da expressão do RNAm de IL6. Coerente com estes dados, o tratamento do EGF resultou no reforço de produção de IL-6 após cultivo celular em meio sem soro. O bloqueio de anticorpos contra a IL-6R inibe a produção de IL-6 e EGF, sendo que IL-6 induz a migração celular. Estes dados sugerem que o estado ativado de STAT3 em carcinomas de ovário pode ocorrer diretamente através da ativação de EGFR ou de IL-6R ou indiretamente através da ativação do receptor de IL-6. Essa ativação de STAT3 sugere uma justificativa para uma combinação de anti-STAT3 e terapia EGFR/IL-6R para suprimir a disseminação peritoneal de câncer de ovário. Além disso, outro estudo demonstrou que a via JAK2/ STAT3 é necessária para sustentar a indução do EGF para desencadear movimento das células cancerosas ${ }^{74}$, concluindo que a ação do EGF em tumores de ovário pela sinalização JAK2/STAT3 pode ser crucial na regulação da metástase.

\subsection{Ativina}

A ativina é um fator importante produzido pelos ovários e o seu papel no câncer epitelial ovariano é pouco definido. ${ }^{75,76}$ Elevados níveis de ativina A no soro sanguíneo, no líquido de cistos ovarianos e em fluido peritoneal de pacientes com câncer ovariano sugerem um papel para este peptídeo no desenvolvimento da doença. Juntamente com os estrógenos, a ativina tem sido um fator associado com o desenvolvimento e a progressão do câncer ovariano epitelial (Drummond et al (2011). ${ }^{76}$ Kubba et al. (2008) ${ }^{77}$ mostraram que a ativina-A tem um papel na biologia do tumor de ovário através da regulação das vias de sinalização Akt e GSK, por reprimir as atividades dessas moléculas sobre a proliferação celular. Ramachandran (2009) ${ }^{75}$ mostrou que a ativina-A estimula a mutiplicação de células do epitélio superficial do ovário e que a proteína bcl-2 aumenta a expressão de ativina. Desta forma, a ativina aumenta a proliferação celular através da via anti-apoptótica bcl-2. No entanto,${ }^{76}$ demonstraram que a ativina pode não exercer efeito sobre a proliferação de linhagens celulares originadas de adenocarcinoma de células claras e adenocarcinoma endometrioide.

\section{Considerações finais}

O câncer de ovário possui incidência significativa na população, porém quase não há expressão clínica, o que dificulta diagnóstico. Tornam-se cada vez 
mais necessários estudos e pesquisas da fisiologia do ovário e de suas disfunções diante do desenvolvimento do câncer, visando medidas de uma possível prevenção ou diagnóstico precoce dessa grave doença. Os diversos tipos de câncer de ovário possuem características moleculares peculiares, prevalências e prognósticos diferentes que devem ser considerados nas análises clínicas e patológicas. O estudo das alterações na expressão de genes para citocinas, fatores de crescimento e seus receptores podem identificar quais as modificações moleculares ocorrem para o favorecimento ou inibição da proliferação celular na carcinogênese ovariana, além de investigar fatores associados que desencadeiam as metástases. Diante do câncer já desenvolvido, necessitando de quimioterapia que restringiria ou anularia a reserva folicular, há estudos que mostram opções viáveis para preservar a fertilidade, como a criopreservação e cultivo de folículos ovarianos.

\begin{abstract}
Ovarian cancer is the most lethal of gynecologic cancer and more difficult to diagnose. Nearly three fourths of malignant tumors of the ovary presents at an advanced stage during early diagnosis. The etiology of ovarian cancer is multifactorial, including reproductive, family and personal factors. Several factors involved in the development of ovarian cancer has being studied, seeking to better understand its development. The tumor originated from the superficial epithelium of the ovary is the most frequent type and it has been associated with alteration in expression of kit ligand $(\mathrm{KL})$, epidermal growth factor receptor (EGF-R), HER, myc, ras and p53. The aim of this review is to describe the characteristics of ovarian tumors and to discuss the influences of gonadotrophins and the changes in gene expression for cytokines, growth factors and their receptors in ovarian tumors.
\end{abstract}

Key-words: Ovarian Cancer. Gene Expression. Biological Markers. Epithelial Neoplasms, Malignant.

\section{Referências}

1. Jemal A, Siegel R, Ward E, Murray T, Xu J, Smigal C, Thun MJ. Cancer statistics. Cancer J Clin. 2006; 56:106-30.

2. Feeley KM, Wells M. Precursor lesions of ovarian epithelial malignancy. Histopathol. 2001; 38: 87-95.

3. Agarwal SK, Chang RJ. Fertility management for women with cancer. Cancer Treat Res. 2007; 138:15-27.

4. Puiffe ME, Le Page C, Mouhim AF, Ziestarska M, Quellet V, Tonin PN, et al. Characterization of ovarian cancer ascites on cell invasion, proliferation, spheroid formation, and gene expression in an in vitro model of epithelial ovarian cancer. Neoplasia. 2007; 9:820-9.

5. Psyrri AK, Kassar M, Yu Z, Bamias A, Weinberger PM, Markakis $S$, et al. Effect of epidermal growth factor receptor expression level on survival in patients with epithelial ovarian cancer. Clin Cancer Res. 2005; 11:8637-43.

6. Seidman JD, Horkayne-Szakaly I, Haiba M, Boice CR, Kurman RJ, Ronnett BM. The histologic type and stage distribution of ovarian carcinomas of surface epithelial origin. Int J Gynecol Pathol. 2004; 23:41-4.

7. Dubeau L. The cell of origin of ovarian epithelial tumors and the ovarian surface epithelium dogma: does the emperor have no clothes? Gynecol Oncol. 1999; 72:437-42.

8. Tammela J, Geisler JP, Eskew PN Jr, Geisler HE. Clear cell carcinoma of the ovary: poor prognosis compared to serous carcinoma. Eur J Gynaecol Oncol. 1998; 19:438-40.

9. Hart WR. Diagnostic challenge of secondary (metastatic) ovarian tumors simulating primary endometrioid and mucinous neoplasms. Pathol Int. 2005; 55:231-43.
10. Richards J. Hormonal control of gene expression in the ovary. Endocr Rev. 1994; 15:725-51.

11. Robker R, Richards J. Hormone-induced proliferation and differentiation of granulosa cells: a coordinated balance of the cell cycle regulators cyclin D2 and p27KIP1. Mol Endocrinol. 1998; 12:924-40.

12. Ji Q, Liu PI, Chen PK, et al. Follicle stimulating hormone-induced growth promotion and gene expression profiles on ovarian surface epithelial cells. Int J Cancer. 2004; 112:803-14.

13. Huang $Y$, Hua K. Activation of the PI3K/AKT pathway mediates FSH-stimulated VEGF expression in ovarian serous cystadenocarcinoma. Cell Research. 2008; 18:780-91.

14. Choi JH, Choi KC, Auersperg N, Leung PC. Gonadotropins activate proteolysis and increase invasion through protein kinase $\mathrm{A}$ and phosphatidylinositol 3-kinase pathways in human epithelial ovarian cancer cells. Cancer Res. 2006; 66:3912-20.

15. Rezepka-Górska I, Chudecka-Gatz A, Kosmowska B. FSH and LH serum/tumor fluid ratios and malignant tumors of the ovary. Endocr Relat Cancer. 2004; 11:315-21.

16. Stouffer R, Grodin M, Davis J, Surwit E. Investigation of binding sites for follicle-stimulating hormone and chorionic gonadotropin in human ovarian cancers. J Clin Endocrinol Metab. 1984; 59:441-6.

17. Graves P, Surwit E, Davis J, Stouffer R. Adenylate cyclase in human ovarian cancers: sensitivity to gonadotropins and nonhormonal activators. Am J Obstet Gynecol. 1985; 153:87782.

18. Lappohn R, Burger H, Bouma J, Bangah M, Krans M, De Bruijn $\mathrm{H}$. Inhibin as a marker for granulosa-cell tumors. N Engl J Med. 1989; 321:790-3. 
19. Jobling T, Mamers P, Healy D, Maclachlan V, Burger H, Quinn $\mathrm{M}$, et al. A prospective study of inhibin in granulosa cell tumors of the ovary. Gynecol Oncol. 1994; 55:285-9.

20. Chu S, Rushdi S, Zumpe E, Mamers P, Healy D, Jobling TH, Fuller P. FSH-regulated gene expression profiles in ovarian tumors and normal ovaries. Mol Hum Reprod. 2002; 8:42633.

21. Strachan L, Murison J, Prestidge R, Sleeman M, Watson J, Kumble K. Cloning and biological activity of epigen, a novel member of the epidermal growth factor superfamily. J Biol Chem. 2001; 276:18265-71.

22. Yarden Y. The EGFR family and its ligands in human cancer: signaling mechanisms and therapeutic opportunities. Eur $\mathrm{J}$ Cancer. 2001; 4:3-8.

23. Mason RA, Morlock EV. EGFR pathway polymorphisms and bladder cancer susceptibility and prognosissis. Carcinogenesis 2009; 30:1155-60.

24. Siemens C, Auersperg N. Serial propagation of human ovarian surface epithelium in tissue culture. J Cell Physiol. 1988; 134:347-56

25. Berchuck A, Rodriguez G, Olt G, Whitaker R, Boente M, Arrick $B$, et al. Regulation of growth of normal ovarian epithelial cells and ovarian cancer cell lines by transforming growth factor. Am J Obstet Gynecol. 1992; 166:676-84.

26. Li Y, Yang J, Dai C, Wu C, Liu Y. Role for integrin-linked kinase in mediating tubular epithelial to mesenchymal transition and renal interstitial fibrogenesis. J Clin Invest. 2003; 112:503-16.

27. Ahmed N, Maines-Bandiera S, Quinn MA, Unger WG, Dedhar $\mathrm{S}$, Auersperg N. Molecular pathways regulating EGF-induced epithlio-mesenchymal transition in human ovarian surface epithelium. Am J Physiol Cell Physiol. 2006; 290:1532-42.

28. Normanno N, Bianco C, De Luca A, Maiello M, Salomon D. Target-based agents against ErbB receptors and their ligands: a novel approach to cancer treatment. Endocr Relat Cancer. 2003; 10:1-21.

29. Colomiere M, Findlay J, Ackland L, Ahmed N. Epidermal growth factor induced ovarian carcinoma cell migration is associated with JAK2/STAT3 signals and changes in the expression and abundance of alpha6beta1 integrin. Inter J Biochem Cell Biol. 2009; 41:1034-45.

30. Poon SL, Hammond GT. Epidermal Growth Factor-Induced GnRH-II Synthesis Contributes to Ovarian Cancer Cell Invasion. Molecular Endocrinology. 2009; 23: 1646-56.

31. Yarden Y, Shilo BZ. SnapShot: EGFR signaling pathway. Cell. 2007; 131:1018.

32. Blank SV, Chang R, Muggia F. Epidermal growth factor receptor inhibitors for the treatment of epithelial ovarian cancer. Oncology. 2005; 19:553-9.

33. Hirano T. Cytokines in autoimmune disease and chronic inflammatory proliferative disease. Cytokine Growth Factor Rev. 2002; 13:297-8.

34. Kryczek I, Grysbos M, Karabon L, Klimczak A, Lange A. IL-6 production in ovarian carcinoma is associated with histiotype and biological characteristics of the tumour and influences local immunity. Br J Cancer. 2000; 82: 621-8.

35. Asschert JG, Vellenga E, Ruiters MH, de Vries EG. Regulation of spontaneous and TNF/IFN-induced IL-6 expression in two human ovarian-carcinoma cell lines. Int J Cancer. 1999; 82:244-9.

36. Syed V, Ulinski G, Mok SC, Ho SM. Reproductive hormoneinduced, STAT3-mediated interleukin 6 action in normal and malignant human ovarian surface epithelial cells. J Natl Cancer Inst. 2002; 94:617-29.
37. Coward J, Kulbe H, Chakravarty P, Leader D, Vassileva V, Leinster DA, et al. Interleukin-6 as a Therapeutic Target in Human Ovarian Cancer. Clin Cancer Res. 2011; 17:6083-96.

38. Lane D, Matte I, Rancourt C, Piché A. Prognostic significance of IL-6 and IL-8 ascites levels in ovarian cancer patients. BMC Cancer. 2011; 11: 210.

39. Feige JN, Gelman L, Michalik L, Desvergne B, Wahli W. From molecular action to physiological outputs: peroxisome proliferator activated receptors are nuclear receptors at the crossroads of key cellular functions. Prog Lipid Res. 2006; 45:120-59.

40. Michalik L, Desvergne B, Wahli W. Peroxisome proliferator activated receptors beta/delta: emerging roles for a previously neglected third family member. Curr Opin Lipidol. 2003; 14:129-35

41. Somasiri A, Howarth A, Goswami D, Dedhar S, Roskelley CD. Overexpression of the integrin-linked kinase mesenchymally transforms mammary epithelial cells. J Cell Sci. 2001; 114:1125-36.

42. Ahmed N, Riley C, Quinn MA. An immunohistochemical perspective of PPAR? and one of its putative targets PDK1 in normal ovaries, benign and malignant ovarian tumours. $\mathrm{Br} J$ Cancer. 2008; 98:1415-24.

43. Yokoyama $Y$, Xin B, Shigeto T, Umemoto M, Kasai-Sakamoto A, Futagami M, et al. Clofibric acid, a peroxisome proliferatoractivated receptor ? ligand, inhibits growth of human ovarian cancer. Mol Cancer Ther. 2007; 6:1379-86.

44. Kim S, Lee JJ, Heo DS. PPAR c ligands induce growth inhibition and apoptosis through p63 and p73 in human ovarian cancer cells. Biochem Biophys Res Commun. 2011; 406:38995.

45. Arboleda MJ, Lyons JF, Kabbinavar FF, Bray MR, Snow BE, Ayala R, et al. Overexpression of AKT2/protein kinase beta leads to up-regulation of beta1 integrins, increased invasion, and metastasis of human breast and ovarian cancer cells. Cancer Res. 2003; 63:196-206.

46. 46. Lu Z, Cox-Hipkin MA, Windsor WT, Boyapati A. 3Phosphoinositide - Dependent Protein Kinase-1 Regulates Proliferation and Survival of Cancer Cells with an Activated Mitogen-Activated Protein Kinase Pathway. Mol. Cancer Res. 2010, 8:421-32.

47. Choi JH, Yang YR, Lee SK, Sun-Hee Kim, Yun-Hee Kim, JooYoung Cha, et al. Potential Inhibition of PDK1/Akt Signaling by Phenothiazines Suppresses Cancer Cell Proliferation and Survival. Annals of the New York Academy of Science. 2008.

48. Ornitz D, Itoh N. Fibroblast growth factors. Genome Biol. 2001; 2:3001-5.

49. Werner S. Keratinocyte growth factor: a unique player in epithelial repair processes. Cytokine Growth Factor Rev. 1998; 2:153-65.

50. Whitworth M, Backen A, Clamp A, Wilson G, Mc Vey R, Friedl A, et al. Regulation of Fibroblast Growth Factor-2 Activity by Human Ovarian Cancer Tumor Endothelium. Clin Cancer Res. 2005; 11:4282-8.

51. Yamamoto S, Konishi I, Nanbu K, Komatsu T, Mandai M, Kuroda $\mathrm{H}$, et al. Immunohistochemical localization of basic fibroblast growth factor (bFGF) during folliculogenesis in the human ovary. Gynecol Endocrinol. 1997; 11:223-30.

52. Berisha B, Steffl M, Amselgruber W, Schams D. Changes in fibroblast growth factor 2 and its receptors in bovine follicles before and after GnRH application and after ovulation. Reproduction. 2006; 131:319-29.

53. Jayson G, Evans G, Pemberton P, Lobley R, Allen T. Basic fibroblast growth factor increases the multiplication and $\mathrm{mi}-$ 
gration of a serum-free derivative of CACO-2 but does not affect differentiation. Cancer Res. 1994; 54:5718-23.

54. Crickard K, Gross J, Crickard U. Basic fibroblast growth factor and receptor expression in human ovarian cancer. Gynecol Oncol. 1994; 55:277-84.

55. Fujimoto J, Ichigo S, Hori M, Hirose R, Sakaguchi H, Tamaya T. Expression of basic fibroblast growth factor and its mRNA in advanced ovarian cancers. Eur J Gynaecol Oncol. 1997; 18:349-52.

56. Masaru K. Cancer genomics and genetics of FGFR2 (Review). Int. Journal of Oncol. 2008; 33: 233-7.

57. O'dell S, Day I. Molecules in focus: insulin-like growth factor II (IGF-II). Int J Biochem Cell Biol. 1998; 30:767-71.

58. Christofori G, Naik P, Hanahan D. A second signal supplied by insulin-like growth factor II in oncogene-induced tumorigenesis. Nature 1994; 369:414-8.

59. Terry KL, Tworoger SS, Gates MA, Cramer DW, Hankinson SE. Common genetic variation in IGF1, IGFBP1 and IGFBP3 and ovarian cancer risk. Carcinogenesis 2009; 30:2042-6.

60. Eckstein N, Servan K, Hildebrandt B, Pölitz A, von Jonquières $G$, Wolf-Kümmeth $S$, et al. Hyperactivation of the insulin-like growth factor receptor i signaling pathway is an essential event for cisplatin resistance of ovarian cancer cells. Cancer Res. 2009; 69:2996-3003.

61. Fleischman R. From white spots to stem cells: the role of the Kit receptor in mammalian development. Trends Genet. 1993; 9:285-90.

62. Ezoe K, Holmes S, Ho L, Bennett C, Bolognia J, Brueton L, et al. Novel mutations and deletions of the KIT (Steel Factor Receptor) gene in human piebaldism. Am J Hum Genet. 1995; 56:58-66.

63. Longley B, Tyrrel L, Lu S, Jacobs P, Tang L, Modlin I. Somatic C-KIT activating mutation in urticaria pigmentosa and aggressive mastocytosis: establishment of clonality in a human mast cell neoplasm. Nat Genet. 1996; 12:312-4.

64. Hirota S, Isozaki K, Moriyama Y, Hashimoto K, Nishida T, Ishiguro S, et al. Gain-of-function mutations of c-kit in human gastrointestinal stromal tumors. Science. 1998; 23:577-80.

65. Cheng L, Roth LM, Zhang S, Wang M, Morton MJ, Zheng W, et al. KIT gene mutation and amplification in dysgerminoma of the ovary. American Cancer Society.2010., DOI: 10.1002/ cncr. 25794

66. Parrot JA, Kim G, Skinner M. Expression and action of kit lingand/stem cell factor in normal human and bovine ovarian surface epitelium and ovarian cancer. Biol Reprod. 2000; 62:1600-9.
67. Teng CB, Diao HL, Ma XH, Xu LB, Yang ZM. Differential expression and activation of Stat3 during mouse embryo implantation and decidualization. Mol Reprod Dev. 2004; 69:110.

68. Chen CL, Loy A, Cen L, Chan C, Hsieh FC, Cheng G, et al. Signal transducer and activator of transcription 3 is involved in cell growth and survival of human rhabdomyosarcoma and osteosarcoma cells. BMC Cancer. 2007; 7:111.

69. Duan Z, Bradner J, Greenberg E, Mazitschek R, Foster R, Mahoney J, Seiden MV. 8-Benzyl-4-oxo-8-azabicyclo[3.2.1] oct-2-ene-6,7-dicarboxylic Acid (SD-1008), a Novel Janus Kinase 2 Inhibitor, Increases Chemotherapy Sensitivity in Human Ovarian Cancer Cells. Mol Pharmacol. 2007; 72:113745.

70. Carbia-Nagashima A, Arzt E. Intracellular proteins and mechanisms involved in the control of gp130/JAK/STAT cytokine signaling. IUBMB Life 2004; 56:83-8.

71. Sriuranpong V, Park JI, Amornphimoltham P, Patel V, Nelkin BD, Gutkind JS. Epidermal growth factor receptor-independent constitutive activation of STAT3 in head and neck squamous cell carcinoma is mediated by the autocrine/paracrine stimulation of the interleukin 6/gp130 cytokine system. Cancer Res. 2003; 63:2948-56.

72. Chan KS, Carbajal S, Kiguchi K, Clifford J, Sano S, DiGiovanni J. Epidermal growth factor receptor-mediated activation of Stat3 during multistage skin carcinogenesis. Cancer Res. 2004; 64:2382-9.

73. Prata Lima MF, Baracat EC, Simoes MJ. Effects of melatonin on the ovarian response to pinealectomy or continuous light in female rats: similarity with polycystic ovary syndrome. Braz. J Med Biol Res. 2004; 37:987-95.

74. Colomiere M, Ward AC, Riley C, Trenerry MK, Cameron-Smith $\mathrm{D}$, Findlay $\mathrm{J}$, et al. Cross talk of signals between EGFR and IL-6R through JAK2/STAT3 mediate epithelial-mesenchymal transition in ovarian carcinomas. Br J Cancer. 2009; 100:13444.

75. Ramachandran A, Marshall ES, Love DR, Baguley BC, Shelling AN. Activin is a potent growth suppressor of epithelial ovarian cancer cells. Cancer Lett. 2009; 285:157-65.

76. Drummond AE, Fuller PJ. Activin and inhibin, estrogens and $\mathrm{NFjB}$, play roles in ovarian tumourigenesis is there crosstalk. Molecular and Cellular Endocrinology. 2011. doi:10.1016/ j.mce.2011.07.033

77. Kubba LA, Antenos M, Rademaker AW, Sturgis CD, Woodruff TK. The role of activin A and Akt/GSK signaling in ovarian tumor biology. Endocrinology. 2008; 149:3809-16. 